\title{
Ti-Si-C Thin Films Produced by Magnetron Sputtering: Correlation Between Physical Properties, Mechanical Properties and Tribological Behavior
}

\author{
L. Cunha ${ }^{1, *}$, F. Vaz ${ }^{1}$, C. Moura ${ }^{1}$, D. Munteanu ${ }^{2}$, C. Ionescu², \\ J. P. Rivièr ${ }^{3}$, and E. Le Bourhis ${ }^{3}$ \\ 1 Physics Department, University of Minho, Campus de Gualtar, 4710-057 Braga, Portugal \\ ${ }^{2}$ Department of Materials Science and Engineering, Transilvania University, 500036 Brasov, Romania \\ ${ }^{3}$ Laboratoire de Métallurgie Physique, Université de Poitiers, 86960 Futuroscope, France
}

\begin{abstract}
Ti-Si-C thin films were deposited onto silicon, stainless steel and high-speed steel substrates by magnetron sputtering, using different chamber configurations. The composition of the produced films was obtained by Electron Probe Micro-Analysis (EPMA) and the structure by X-ray diffraction (XRD). The hardness and residual stresses were obtained by depth-sensing indentation and substrate deflection measurements (using Stoney's equation), respectively. The tribological behavior of the produced films was studied by pin-on-disc. The increase of the concentration of non-metallic elements (carbon and silicon) caused significant changes in their properties. Structural analysis revealed the possibility of the coexistence of different phases in the prepared films, namely Ti metallic phase ( $\alpha$-Ti or $\beta$-Ti) in the films with higher Ti content. The coatings with highest carbon contents, exhibited mainly a sub-stoichiometric fcc $\mathrm{NaCl}$ TiC-type structure. These structural changes were also confirmed by resistivity measurements, whose values ranged from $10^{3} \Omega / \mathrm{sq}$ for low non-metal concentration, up to $10^{6} \Omega / \mathrm{sq}$ for the highest metalloid concentration. A strong increase of hardness and residual stresses was observed with the increase of the non-metal concentration in the films. The hardness $(\mathrm{H})$ values ranged between 11 and $27 \mathrm{GPa}$, with a clear dependence on both crystalline structure and composition features. Following the mechanical behavior, the tribological results showed similar trends, with both friction coefficients and wear revealing also a straight correlation with the composition and crystalline structure of the coatings.
\end{abstract}

Keywords: Ti-Si-C Coatings, Multifunctional Coatings, Sputtering.

\section{INTRODUCTION}

During last years, a significant amount of work has been done on nanostructured coatings, deposited by conventional PVD methods such as sputtering. One may find scientific studies referring several different coatings systems that have been developed for different applications or motivations. Most of them were to develop hard, tough, low friction and thermal stable coatings. ${ }^{1-10}$ The motivation of a significant part of these studies was mainly related to the influence of the grain structure as well as to the grain boundaries on the properties and performance of the coatings. Taking into account their mechanical behavior, the decrease in the grain size, and the control of the composition of the grain boundaries, allows improvements in the mechanical strength and in the toughness of the films,

*Author to whom correspondence should be addressed. by impeding the dislocations or avoiding the grain boundary sliding processes. Positive results have been recently achieved in polycrystalline nanostructured materials, composed of atoms with different chemical reactivity, which then may develop different types of phases. Phase segregation may occur during the coatings deposition or by thermal annealing, giving rise to what may be called a multiphase material. These procedures may promote the formation of crystalline phases surrounded by other types of phases within the grain boundaries. Nanocomposite materials may be produced such as the well-known $\mathrm{Me}-\mathrm{Si}-\mathrm{N}$ system (where Me stands for Ti, V or W), in which Me-N nanocrystallites may be embedded in an amorphous $\mathrm{Si}-\mathrm{N}$ matrix. ${ }^{11}$

In spite of the significant amount of case-success in these kinds of nanocomposite, and as a result of the increasing demands of several mechanical/tribological 
applications/devices, increasing interest is being dedicated to other multifunctional systems. In this sense, the $\mathrm{Me}-\mathrm{Si}-\mathrm{C}$ system (where Me stands for a transition metal, most commonly $\mathrm{Ti}$ ), is being increasingly studied for wear protection applications. ${ }^{12}$ Recently the research on the this systems has turned towards a new family of materials, the so-called MAX phases. ${ }^{13,14}$ The successful synthesis of MAX phases as a thin film has drawn much attention to these unique materials and introduced a new field of potential applications. ${ }^{15-18}$ This is a group of ternary systems that combines the benefits of ceramics (resistance against oxidation and a high decomposition temperature) with metals (ductility, electrical and thermal conductivity, thermal shock resistance). ${ }^{15}$ However there is a major disadvantage. Most of the MAX phase family thin films can only be synthesized at temperatures above $700{ }^{\circ} \mathrm{C}$ in most cases, and on textured or single-crystalline substrates. ${ }^{19-21}$ The choice of technologically relevant substrates is constrained, and thus further and extensive research programs are being developed. Lower growth temperatures, on the other hand, result in nanocomposite materials, which have been faced as promising candidates for protective coating in electrical friction contacts, owing to their metallic conductivity and resistance to wear and corrosion. ${ }^{14,19}$ Taking these features as a starting point and following the authors previous works dealing with Ti-based coatings, ${ }^{2,22-25}$ the purpose of this paper consists on the preparation and study of Ti-Si-C thin films, deposited by combined dc/rf magnetron co-sputtering in the low-temperature range. Within the framework of previous studies, results have demonstrated that a significant variation in the electrical, optical and mechanical properties of the as-deposited films was achieved, ${ }^{23,24}$ opening a wide variety of possible applications for such coating materials. Moreover, it is already known some of the advantages that can be obtained by the doping of $\mathrm{Ti}-\mathrm{N}$ coatings with $\mathrm{Si}^{2,26}$ Thus, the driving force for this work consists on the understanding of the advantages that might be obtained by joining these two systems, preparing a ternary system of the type Ti-Si-C, but using low temperature depositions. The paper gives particular emphasis to the physical, structural and mechanical properties, and tribological behavior of the prepared films, with a close correlation with the materials composition.

\section{EXPERIMENTAL PROCEDURE}

The Ti-Si-C films were synthesized by magnetron sputtering, using two targets: a titanium target, connected to a dc power unit, with current densities varying from 1.6 to $3.2 \mathrm{~mA} / \mathrm{cm}^{2}$; and a carbon target, connected to a rf power unit, with applied power densities varying from 0.32 to $1.59 \mathrm{~W} / \mathrm{cm}^{2}$. In order to vary the $\mathrm{Si}$ content in the samples, different amounts of silicon pellets were placed on the $\mathrm{Ti}$ and $\mathrm{C}$ targets, within the erosion zones. For all depositions, the substrate holder was sweeping over the two targets with a constant frequency of 5 sweeps $/ \mathrm{min}$. Substrate temperature $\left(300^{\circ} \mathrm{C}\right)$, dc substrate bias $(-50 \mathrm{~V})$, target to substrate distance $(65 \mathrm{~mm})$ and argon flow rate (100 sccm-partial pressure of $0.3 \mathrm{~Pa}$ ) were kept constant during all the experiments.

The chemical composition of the coatings was investigated with a Cameca SX-50 Electron Probe Micro Analysis (EPMA), operating at $15 \mathrm{keV}$ as acceleration voltage The elemental quantification was performed using standards and applying a ZAF correction to the results. The structure and phase distribution of the coatings were obtained by X-ray diffraction (XRD), using a Philips $\mathrm{X}$ 'pert diffractometer, operating with $\mathrm{Co}_{\alpha}$ radiation, in a Bragg-Brentano configuration.

The residual stresses, $\sigma_{\mathrm{r}}$, were obtained by the deflection method and applying the Stoney's equation, using substrate curvature radii, before and after coating deposition Film's hardness and Young's modulus were determined from the loading and unloading curves, carried out with an ultra low load-depth sensing Berkovich nanoindenter from CSM Instruments. The maximum load used was $30 \mathrm{mN}$, with a loading time of $30 \mathrm{~s}$, holding $30 \mathrm{~s}$ and unloading in $30 \mathrm{~s}$, producing an average number of 15 indentations per sample.

The dynamic friction coefficient and the wear behavior of the coatings have been estimated using a ball-on-disk tribosystem from CSM Instruments. The static partner was a $6 \mathrm{~mm}$ radius $100 \mathrm{Cr} 6$ ball. Wear rates for both the ball and the samples were calculated from the volume of material loss during a specific friction run. The calculation of the worn track section for each sample was also done using a profilometer, Taylor Hobson type. For all wear tests, the annular type wear surfaces were characterized by a wear track of $10 \mathrm{~mm}$ in diameter. It was used a constant load of $5 \mathrm{~N}$ and a linear speed of the rotating plateau was $4.8 \mathrm{~cm} / \mathrm{s}$. The maximum number of laps was 450 . Before all the wear tests, the samples, the sliding half-couples and the balls were cleaned with isopropanol. The environmental conditions for all tribological tests were: $T=24^{\circ} \mathrm{C}$ and $30 \%$ of relative humidity.

Electrical resistivity was deduced from sheet resistance measurements at room temperature, using the four-point probe method. The characterization of film's lightness factor was computed using a commercial MINOLTA CM$2600 \mathrm{~d}$ portable spectrophotometer with a wavelength range from 400 to $700 \mathrm{~nm}$, using diffused illumination at an $8^{\circ}$ viewing angle. The spectrophotometer was equipped with a $52-\mathrm{mm}$ diameter integrating sphere and three pulsed xenon lamps. The observer was placed at a $10^{\circ}$ angle. Lightness factor was computed under the standard CIE illuminant D65-specular component excluded-and represented in the CIELAB 1976 color space. ${ }^{27,28}$ 


\section{RESULTS AND DISCUSSION}

\subsection{Composition Analysis}

The variable deposition conditions and the thickness of the films, measured by ball cratering (CSM calotest), are presented in the Table I. In the table, the identification of the samples is based on the corresponding atomic composition, normalized to the $\mathrm{Ti}$ atomic content (e.g., $\mathrm{TiSi}_{0.11} \mathrm{C}_{0.04}$ means that $\mathrm{Si}$ and $\mathrm{C}$ atomic concentrations are $11 \%$ and $4 \%$ of Ti concentration, respectively).

The composition of the as-deposited samples as a function of $\mathrm{P}_{\mathrm{C}} / \mathrm{I}_{\mathrm{Ti}}$ ratio $\left(\mathrm{P}_{\mathrm{C}}\right.$ stands for the if power applied to $\mathrm{C}$ target and $\mathrm{I}_{\mathrm{Ti}}$ corresponds to the DC current applied to Ti target) are presented in Figure 1(a). As expected, an increase of the C content from 3.9 at.\% to 44.2 at.\%, and a systematic decrease of the Ti content from 81.5 at.\% to 48.8 at.\%, were observed with the increase of the $\mathrm{P}_{\mathrm{C}} / \mathrm{I}_{\mathrm{Ti}}$ ratio. The silicon content shows a two fold behavior, where the samples with the highest $\mathrm{Ti}$ contents-from 81.5 to 67.4 at.\% (and lowest $\mathrm{C}$ contents) present higher Si contents (between 8 and 9.5 at.\%), while the others revealed significantly lower amounts of this element. The reason is mainly due to the lower number of Si pellets that were inserted in the $\mathrm{C}$ target (5). Plotting the atomic concentration ratios, $\mathrm{C} / \mathrm{Ti}, \mathrm{Si} / \mathrm{Ti}$ and $(\mathrm{C}+\mathrm{Si}) / \mathrm{Ti}$ as a function of the target power ratio, $\mathrm{P}_{\mathrm{C}} / \mathrm{I}_{\mathrm{Ti}}$ (see Fig. 1(b)), it is possible to show the existence of two distinct regions. The first one, corresponding to target ratios, $\mathrm{P}_{\mathrm{C}} / \mathrm{I}_{\mathrm{T}}$, up to $500 \mathrm{~W} / \mathrm{A}$, where the samples revealed $\mathrm{Si} / \mathrm{Ti}$ atomic ratios between 0.10 and 0.12 , and relatively low $\mathrm{C} / \mathrm{Ti}$ atomic ratios (below 0.31 ). Due to the higher Ti content in comparison to both $\mathrm{C}$ and $\mathrm{Si}$, this zone will be noted in the text as a $\mathrm{Ti}$ rich zone. The second zone corresponds to the region where the films where prepared with higher target power ratios, $\mathrm{P}_{\mathrm{C}} / \mathrm{I}_{\mathrm{Ti}}$, with the $\mathrm{C} / \mathrm{Ti}$ atomic ratios around 0.9. In this region, the $\mathrm{Si} / \mathrm{Ti}$ is now relatively low and thus it will be noted throughout the text as a $\mathrm{Si}$ doped $\mathrm{TiC}_{x}$ zone. These two different zones will facilitate the discussion of the results in the next sections.

Table I. Deposition parameters and thickness $\left(t_{\mathrm{F}}\right)$ of Ti-Si-C films. The identification of the samples is based on the corresponding atomic composition normalized to the $\mathrm{Ti}$ atomic content.

\begin{tabular}{lccccc}
\hline & \multicolumn{5}{c}{ Deposition parameters } \\
\cline { 2 - 5 } & $\mathrm{P}_{\mathrm{C}}$ & $\mathrm{I}_{\mathrm{Ti}}$ & \# Si & $\mathrm{P}_{\mathrm{C}} / \mathrm{I}_{\mathrm{Ti}}$ & $t_{\mathrm{c}}$ \\
Sample & $(\mathrm{W})$ & $(\mathrm{A})$ & pellets & $(\mathrm{W} / \mathrm{A})$ & {$[\mu \mathrm{m}]$} \\
\hline $\mathrm{TiSi}_{0.11} \mathrm{C}_{0.04}$ & 100 & 1.0 & 10 & 100 & 2.0 \\
$\mathrm{TiSi}_{0.10} \mathrm{C}_{0.10}$ & 200 & 1.0 & 10 & 200 & 2.0 \\
$\mathrm{TiSi}_{0.10} \mathrm{C}_{0.19}$ & 300 & 1.0 & 10 & 300 & 2.4 \\
$\mathrm{TiSi}_{0.12} \mathrm{C}_{0.30}$ & 400 & 1.0 & 10 & 400 & 1.9 \\
$\mathrm{TiSi}_{0.01} \mathrm{C}_{0.36}$ & 500 & 1.0 & 5 & 500 & 2.0 \\
$\mathrm{TiSi}_{0.05} \mathrm{C}_{0.84}$ & 500 & 0.5 & 5 & 1000 & 1.9 \\
$\mathrm{TiSi}_{0.10} \mathrm{C}_{0.90}$ & 500 & 0.5 & 10 & 1000 & 1.6 \\
\hline
\end{tabular}
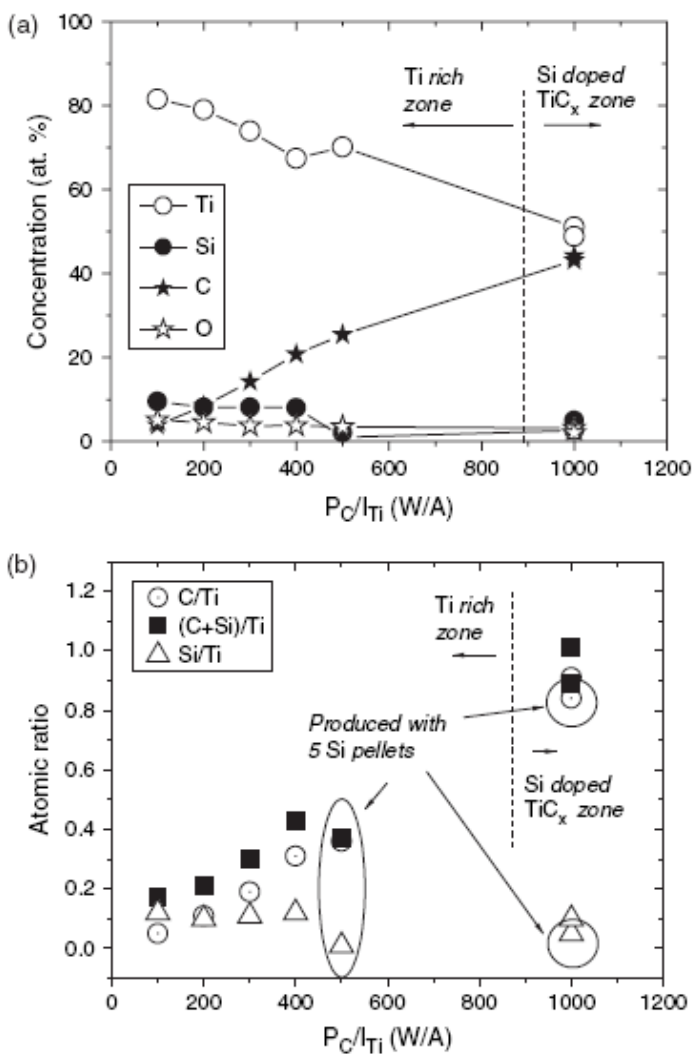

Fig. 1. (a) Atomic concentration of Ti-Si-C films as a function of $\mathrm{P}_{\mathrm{C}} / \mathrm{I}_{\mathrm{T}}$ ratio. (b) Atomic concentration ratios of $\mathrm{Ti}-\mathrm{Si}-\mathrm{C}$ films as a function of $\mathrm{P}_{\mathrm{C}} / \mathrm{I}_{\mathrm{Ti}}$ ratio.

\subsection{Structural Evolution}

Analyzing the XRD patterns of the samples within the Ti rich zone (Fig. 2(a)) it is not an easy task because only one diffraction peak is clearly detected in the analyzed region ( $2 \theta$ was scanned between 20 and $80^{\circ}$ ). Anyway we may find that the detected peak in the sample with the lowest $(\mathrm{C}+\mathrm{Si}) / \mathrm{Ti}$ atomic ratio $\left(\mathrm{TiSi}_{0.11} \mathrm{C}_{0.04}\right)$ is located close to the angular position of the reflection on planes (002) of $\alpha$-Ti (ICDD card nr. 44-1294). This peak is slightly shifted to higher angles probably due to substitution of Ti atoms by smaller $\mathrm{C}$ or $\mathrm{Si}$ atoms in the $\alpha$-Ti structure, causing a decrease in lattice parameters and some lattice distortion. Another possibility is the insertion of $\mathrm{C}$ and/or Si atoms in $\alpha$-Ti structure interstitial positions. In this case, the lattice parameter should increase, but it is not excluded the possibility of a decrease of the lattice parameter in orthogonal directions. The increase of $\mathrm{C}$ content, consequence of the increase of the $\mathrm{P}_{\mathrm{C}} / \mathrm{I}_{\mathrm{Ti}}$ ratio, causes a constant shift of the only peak detected in the XRD patterns of each of the samples, to lower angular positions, approaching the position of the reflection in (111) planes of the fcc structure characteristic of TiC (ICDD card nr. 32-1383). Although, 

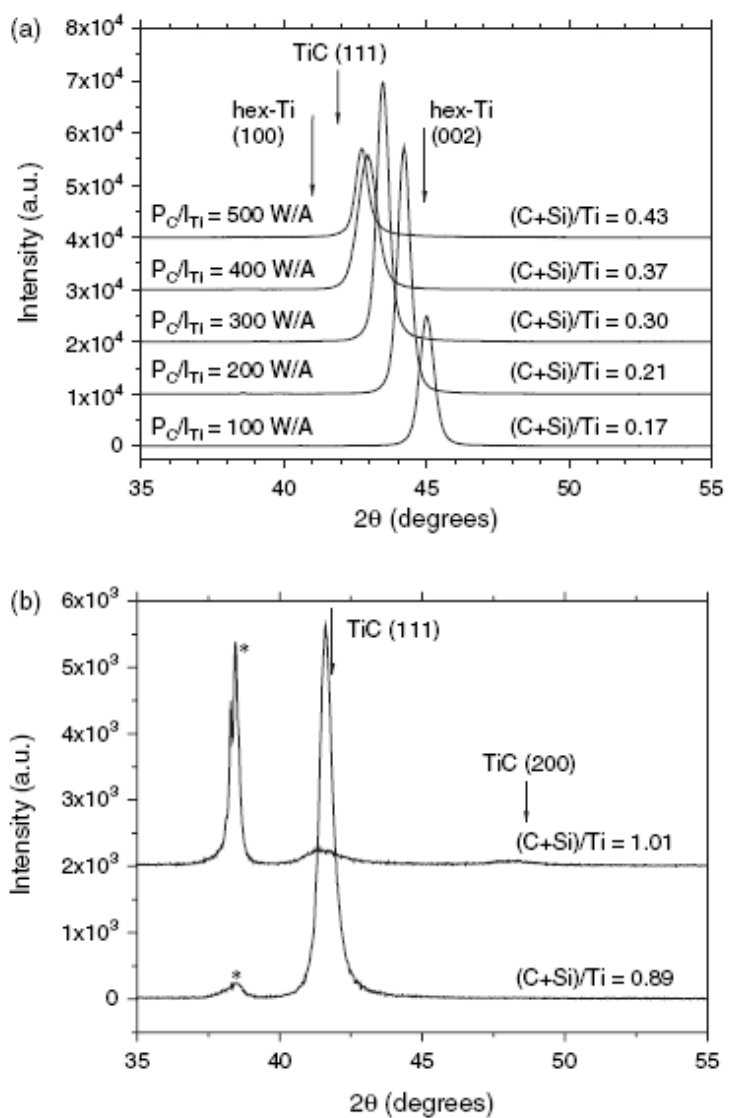

Fig. 2. XRD patterns of Ti-Si-C films: (a) films of the Ti rich zone: (b) films of the $\mathrm{Si}$ doped $\mathrm{TiC}_{x}$ zone (*- substrate peaks).

even for the sample with higher $\mathrm{C}$ and $\mathrm{Si}$ contents within this $\mathrm{Ti}$ rich zone $\left(\mathrm{TiSi}_{0.01} \mathrm{C}_{0.36}\right)$, the peak position is too far apart to be indexed to a typical fcc $\mathrm{NaCl}$ type $\mathrm{TiC}$ structure. In fact, for the remaining samples of this zone, the angular positions are not coherent with any of the previously defined phases, or even with $\beta$-Ti (ICDD card nr. 44-1288), $\mathrm{Ti}_{5} \mathrm{Si}_{3}$ phase (ICDD card nr. 29-1362) or $\mathrm{TiSi}_{2}$ phase (ICDD card nr. 35-0785), suggesting the existence of films that have developed metastable-type phases.

The XRD patterns of the samples from the Si doped $\mathrm{TiC}_{x}$ zone are significantly different (Fig. 2(b)). First of all, a higher number of peaks are detected. A closer look to the diffractograms, and considering both the chemical composition and the peak positions, allows to claim that the $\mathrm{TiSi}_{0.05} \mathrm{C}_{0.84}$ sample exhibits mainly a sub-stoichiometric fcc $\mathrm{NaCl}$ type $\mathrm{TiC}$ structure, with a (111) preferential orientation. This is not a surprising result taking into account the previous results of the authors on the Ti-C system for sub-stoichiometric coatings, ${ }^{23}$ or even those of Kusano et al. ${ }^{29}$ for coatings prepared with $\mathrm{C} / \mathrm{Ti}>0.18$, which exhibited a fcc TiC-type structure (in this work's case $\mathrm{C} / \mathrm{Ti}=0.89$ ). Anyway our work does not confirm Kusanos's results for the samples belonging to Ti rich zone

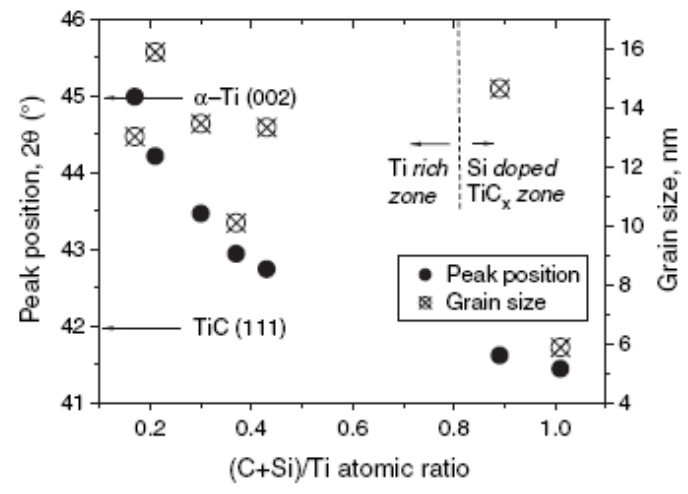

Fig. 3. Angular position of the most intense XRD peaks, and correspondent grain size of $\mathrm{Ti}-\mathrm{Si}-\mathrm{C}$ films, as function $(\mathrm{C}+\mathrm{Si}) / \mathrm{Ti}$ atomic ratio.

$(\mathrm{C} / \mathrm{Ti} \leq 0.36)$. It is very common to have PVD (111) oriented fcc-type compounds when using low adatom energy (low deposition temperature and/or low bias voltages), since this is the lowest density plan in the $\mathrm{NaCl}$ type structure. The sample with highest non metal content $\left(\mathrm{TiSi}_{0.10} \mathrm{C}_{0.90}\right)$ presents two relatively broad peaks that may be indexed to reflection on (111) and (200) planes of fcc $\mathrm{NaCl}$ type $\mathrm{TiC}$ structure. The broader peaks indicate a tendency for amorphization, probably due to higher $\mathrm{Si}$ content (twice higher when compared to the sample $\mathrm{TiSi}_{0.05} \mathrm{C}_{0.84}$ ). There is the possibility of having some $\mathrm{Si}$ atoms occupying vacancies in the sub-stoichiometric $\mathrm{TiC}_{x}$ structure causing significant lattice distortions $\left(r_{\mathrm{Si}} \approx 1.6 r_{\mathrm{C}}\right)^{30}$

No MAX phase type compounds were detected, which may result from the high $\mathrm{Ti}$ concentration in the films of the Ti rich zone and the low temperatures during the deposition process. ${ }^{31}$

Fitting the most intense XRD peaks by a Pseudo-Voigt function the grain size was estimated and it is represented in Figure 3. The results have consequence in physical and mechanical properties as it would be discussed in next sections. This figure also evidences the dislocation of the peaks to lower angular positions. As reference, the unconstrained angular positions of $\alpha$-Ti (002) and fcc TiC (111) peak positions are also represented.

\subsection{Optical and Electrical Results}

The electrical resistivity of a material is mainly determined by the intrinsic properties, defects and temperature (thermal vibrations). In the set of analyzed films, the variations in films composition and the consequent structural changes that are induced strongly influence their electrical and optical properties. The electrical and optical results may be seen in Figure 4. Once again, the two different zones are perfectly identifiable. When $\mathrm{C}$ content in nc-TiSiC is increased, the films continuously loose their metallic character in terms of both optical characteristics and resistivity. In terms of electrical properties, the surface resistivity of 

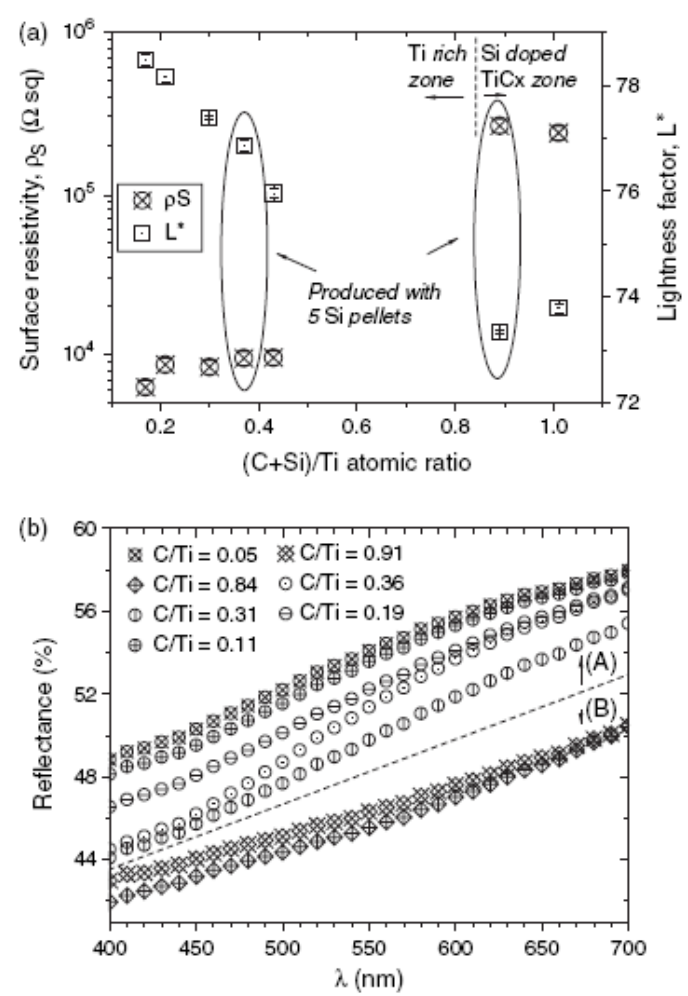

Fig. 4. Electrical and optical properties of Ti-Si-C films: (a) Electrical surface resistivity and lightness factor as a function of $(\mathrm{C}+\mathrm{Si}) / \mathrm{Ti}$ atomic ratio; (b) Reflectance spectra in the visible region ((A) Ti rich zone; (B) Si doped $\mathrm{TiC}_{x}$ zone).

the Ti rich zone samples is two orders of magnitude lower than that of the samples of the $\mathrm{Si}$ doped $\mathrm{TiC}_{x}$ zone. This behavior is mainly attributed to the significantly different Ti content of the films and to the difference in structure of the films of the different zones. It is a change from a dominant metallic bonding regime ( $\mathrm{Ti}$ rich zone) to a dominant covalent bonding regime ( $\mathrm{Si}$ doped $\mathrm{TiC}_{x}$ zone). Within the Ti rich zone, the surface resistivity increases with the decrease of the Ti content in the films (increasing $\mathrm{C}$ content). The small increase of the electrical resistivity with the increasing $\mathrm{C}$ concentration in the Ti rich zone is probably related with the increase of impurity defects as mentioned in the structural analysis: for low $\mathrm{C}$ concentrations, the $\mathrm{C}$ atoms occupy substitutional or interstitial positions within the hexagonal $\alpha$-Ti structure, and thus increasing the material's resistivity. This fact is supported by the broadening of the diffraction peaks (Fig. 2(a)), indicating smaller grains and large microstrains that result in the vanishing of lattice order and increased resistivity. For the highest $\mathrm{C}$ contents, XRD diffractograms showed a structural change from $\alpha$-Ti to a TiC-type structure. Ti-Ti chemical bonds (even with some dopants) are more metallic than those of $\mathrm{Ti}-\mathrm{C}$, which are more covalent. Changing the structure of the films by increasing the $\mathrm{C}$ content in the TiSiC nanocrystals, as the case of the films from the $\mathrm{Si}$ doped $\mathrm{TiC}_{x}$ zone, reduces the free electron density, and thus increasing the resistivity. This induces also a shift in the Fermi level to lower energy, and interband transitions occur at lower photon energies, $E_{\text {photon }}{ }^{32}$

The optical results are coherent with those of electrical characterization presented above. The lightness factor is relatively high (above $70 \%$ for all the samples), but decreases with the decrease of Ti content in the films. As the $(\mathrm{C}+\mathrm{Si}) / \mathrm{Ti}$ ratio increases, the metallic character of the films decreases. In Figure 4(b) it is depicted the reflectance spectra of the samples within the visible region. The shape of the spectra is similar to that one of metallic samples, but in general, when $\mathrm{Ti}$ content decreases the reflectance also decreases.

\subsection{Mechanical Characterization}

Figure 5(a) shows the hardness and the residual stresses of the $\mathrm{Ti}-\mathrm{Si}-\mathrm{C}$ films as a function of $(\mathrm{C}+\mathrm{Si}) / \mathrm{Ti}$ ratio. The films belonging to the Ti rich zone present hardness values higher than the hardness values of pure Ti films found in literature $\left(8 \mathrm{GPa}^{33}\right)$. This result may be explained again by the $\mathrm{C}$ and/or $\mathrm{Si}$ doping of $\mathrm{Ti}$ growing structures, and thus,
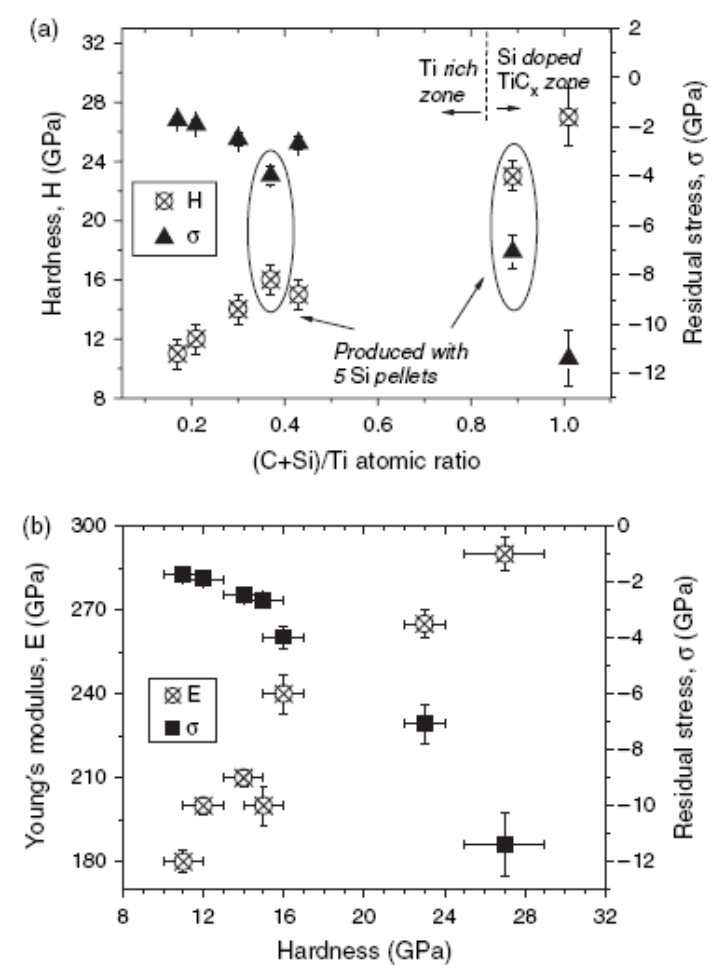

Fig. 5. Mechanical properties of Ti-Si-C films: (a) Hardness and residual stress as a function of $(\mathrm{C}+\mathrm{Si}) / \mathrm{Ti}$ atomic ratio; (b) Young's modulus and residual stress as a function of the hardness. 
a hardening effect by the lattice distortions may be present. Moreover, looking again to Figure 2(a), one may see the progressive dislocation for lower angles of the diffraction peak of each sample and thus, associate this dislocation with the increase of $(\mathrm{C}+\mathrm{Si})$ content in the films. The insertion of an increasing number of $\mathrm{C}$ and/or $\mathrm{Si}$ atoms in the Ti structure may produce metastable-type phases with lattice distortions, inducing an increase of the compressive stress state and thus increasing the hardness of the films.

The films belonging to the $\mathrm{Si}$ doped $\mathrm{TiC}_{x}$ zone present hardness values with similar magnitude of those found in literature for stoichiometric $\mathrm{TiC}\left(25 \mathrm{GPa}^{34,35}\right)$. One should keep in mind that the XRD patterns of these two films (Fig. 2(b)) reveal a fcc $\mathrm{TiC}_{x}$-type structure. The difractogram of the sample with highest $(\mathrm{C}+\mathrm{Si}) / \mathrm{Ti}$ ratio $\left(\mathrm{TiSi}_{0.10} \mathrm{C}_{0.90}\right)$ shows relatively broad peaks and the sample presents the highest hardness (and residual stress) values. This result seems consistent with small $\mathrm{TiC}$ grains embedded in an amorphous matrix containing probably $\mathrm{SiC}_{x}$ and/or $\mathrm{TiSi}_{x}$ and/or amorphous carbon (a-C). Nevertheless, if the samples composition and the possible phase evolution results are taken into account, and simple hardness calculations based on a phase "mixture" rule is performed, the obtained results can be approximately reproduced. This means that most probably it is the effect of phase formation that is ruling the observed behavior, i.e., the low hardness value is due to the high amount of Ti in the coatings. Anyway, the effect of the different crystallinity of the films is, as mentioned previously, also playing an important role. It is well-known that the decreasing grain size increases the grain boundary scattering and thus the film resistivity should increase. ${ }^{36}$ Nevertheless, Figure 3 shows that the two samples from $\mathrm{Si}$ doped $\mathrm{TiC}_{x}$ zone have grown with significantly different grain sizes (14.6 nm and $5.9 \mathrm{~nm}$ ) but with very similar resistivity values (Fig. 4). This results shows that although the different size of grains may have a contribution on the carrier transport properties, it is most likely to be the different bonding conditions, an the correspondent changes in the structural arrangements (defects, etc.) of the films that are playing the most fundamental roles.

Figure 5(b) correlates the Young's modulus and residual stress of the Ti-Si-C films with the hardness. At is expected, the Young's modulus varies almost linearly with the hardness. The residual stress varies with the hardness almost linearly, meaning that the changes induced in the films structure, causing the increasing compressive stresses, induce an increase in hardness, as stated before.

\subsection{Tribological Behavior}

Regarding the tribological behavior of the analyzed coatings, the samples wear rate and the dynamic friction coefficient (between the coating and the $100 \mathrm{Cr} 6$ test ball) as a function of the $(\mathrm{C}+\mathrm{Si}) / \mathrm{Ti}$ atomic ratio is shown in

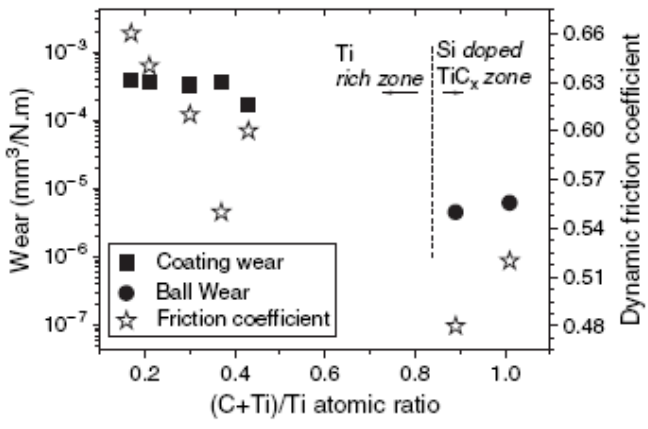

Fig. 6. Tribological behaviour of Ti-Si-C films: Coating wear, test ball wear and dynamic friction coefficient as a function of $(\mathrm{C}+\mathrm{Si}) / \mathrm{Ti}$ atomic ratio.

Figure 6 . From this figure, and once again, it can be clearly observed the existence of two distinct behaviors: that one of the $\mathrm{Si}$ doped $\mathrm{TiC}_{x}$ zone and the one of the $\mathrm{Ti}$ rich zone. The best wear behavior is provided by the samples belonging to the $\mathrm{Si}$ doped $\mathrm{TiC}_{x}$ zone. Within the system resolution, it was not detected any coating wear, but it was detected wear on the test ball. One should keep in mind that these samples presented the highest hardness, Young's modulus and residual stress values. Moreover, the composition is not far from stoichiometric $\mathrm{TiC}$ and in fact, the structure reveals $\mathrm{TiC}$ diffraction peaks.

The samples of the Ti rich zone show a tendency for a decrease of the wear rate with the increase of the $(\mathrm{C}+\mathrm{Si}) / \mathrm{Ti}$ ratio. This means as well that the wear rate decreases with the decrease of friction coefficient and with the increase of the hardness, the compressive residual stress and, in consequence, of the $(\mathrm{C}+\mathrm{Si}) / \mathrm{Ti}$ atomic ratio. In this set of samples it was not detected any wear of the test ball.

From the results plotted in this figure, the main observation that can be drawn is that the dynamic friction coefficient of the samples decreases, in general, with the increase of the $(\mathrm{C}+\mathrm{Si}) / \mathrm{Ti}$ atomic ratio, and most important that of $\mathrm{C}$ content.

\section{CONCLUSIONS}

Ti-Si-C coatings have been deposited by magnetron sputtering. The produced coatings were divided in two different zones according to their composition and structure: $\mathrm{Ti}$ rich zone, for those with $\mathrm{Ti}$ atomic concentration higher than $65 \%$; and $\mathrm{Si}$ doped $\mathrm{TiC}_{x}$ zone, for those with a $\mathrm{C} / \mathrm{Ti}$ ratio higher than 0.83 and $\mathrm{TiC}$ assigned diffraction peaks.

The films within the $\mathrm{Ti}$ rich zone revealed lower surface resistivity (but increasing with the decrease of Ti content), higher reflectance and lightness factor (both decreasing with the decrease of Ti content).

The films within the $\mathrm{Si}$ doped $\mathrm{TiC}_{x}$ zone revealed better mechanical properties and the tribological behavior, 
mainly attributed to the existence of fcc $\mathrm{NaCl}$ type $\mathrm{TiC}_{x}$ grains, probably embedded in an amorphous $\mathrm{SiC}_{x}$ matrix.

\section{References and Notes}

1. J. Musil, Surf. Coat. Technol. 125, 322 (2000)

2. F. Vaz, L. Rebouta, P. Goudeau, J. Pacaud, H. Garem, J. P. Rivière, A. Cavaleiro, and E. Alves, Surf. Coat. Technol. 133-134, 307 (2000).

3. A. A. Voevodin, J. S. Zabinski, and C. Muratore, Tsinghua Sci. Technol. 10,665 (2005).

4. A. Cavaleiro and J. T. M. De Hosson, Nanostructured Coatings, Springer, New York (2006).

5. S. Zhang, D. Sun, Y. Fu, and H. Du, Surf. Coat. Technol. 198, 2 (2005).

6. Y. T. Pei, D. Galvan, and J. Th. M. De Hosson, Acta Mater. 53, 4505 (2005).

7. S. Veprek, M. G. J. Veprek-Heijman, P. Karvankova, and J. Prochazka, Thin Solid Films 476, 1 (2005).

8. P. H. Mayrhofer, C. Mitterer, L. Hultman, and H. Clemens, Prog. Mater. Sci. 51, 1032 (2006)

9. A. Raveh, I. Zukerman, R. Shneck, R. Avni, and I. Fried, Surf. Coat. Technol. 201, 6136 (2007).

10. A. Cavaleiro and C. Louro, Surf. Coat. Technol. 201, 6154 (2007).

11. S. Veprek, Surf. Coat. Technol. 97, 15 (1997).

12. T. Zehnder, J. Matthey, P. Schwaller, A. Klein, P.-A. Steinmann, and J. Patscheider, Surf. Coat. Technol. 163-164, 238 (2003).

13. M. W. Barsoum, Prog. Solid State Chem. 28, 201 (2000).

14. H. Högberg, L. Hultman, J. Emmerlich, T. Joelsson, P. Eklund, J. M. Molina-Aldareguia, J.-P. Palmquist, O. Wilhelmsson, and U. Jansson, Surf. Coat. Technol. 193, 6 (2005).

15. M. W. Barsoum and T. El-Raghy, Am. Sci. 89, 334 (2001).

16. J.-P. Palmquist, U. Jansson, T. Seppänen, P. O. A. Persson, J. Birch, L. Hultman, and P. Isberg, Appl. Phys. Lett. 81, 835 (2002).

17. M. W. Barsoum, M. Radovic, Encyclopedia of Materials: Science and Technology, edited by R. W. C. K. H. J. Buschow, M. C. Flemings, E. J. Kramer, S. Mahajan, and P. Veyssiere, Elsevier, Amsterdam (2004)

18. M. W. Barsoum and T. El-Raghy, J. Am. Ceram. Soc. 79, 1953 (1996).

19. P. Eklund, J. Emmerlich, H. Högberg, O. Wilhelmsson, P. Isberg, J. Birch, P. O. A. Persson, U. Jansson, and L. Hultman, J. Vac. Sci. Technol., B 23, 2486 (2005)
20. J. Emmerlich, J.-P. Palmquist, H. Högberg, J. Molina, Zs. Czigány, S. Sasvári, P. O. Å. Persson, U. Jansson, and L. Hultman, J. Appl. Phys. 96, 4817 (2004).

21. J.-P. Palmquist, S. Li, P. O. Å. Persson, J. Emmerlich, O. Wilhelmsson, H. Högberg, M. I. Katsnelson, B. Johansson, R. Ahuja, O. Eriksson, L. Hultman, and U. Jansson, Phys. Rev. B 70, 165401 (2004)

22. F. Vaz, P. Cerqueira, L. Rebouta, S. M. C. Nascimento, E. Alves, Ph. Goudeau, J. P. Rivière, K. Pischow, and J. de Rijk, Thin Solid Films 447-448, 449 (2004)

23. A. C. Fernandes, P. Carvalho, F. Vaz, S. Lanceros-Méndez, A. V. Machado, N. M. G. Parreira, J. F. Pierson, and N. Martin, Thin Solid Films 515, 866 (2006).

24. A. C. Fernandes, F. Vaz, L. Rebouta, A. Pinto, E. Alves, N. M. G. Parreira, Ph. Goudeau, E. Le Bourhis, and J. P. Rivière, Surf. Coat. Technol. 201, 5587 (2007)

25. C. Lopes, N. M. G. Parreira, S. Carvalho, A. Cavaleiro, J. P. Rivière, E. Le Bourhis, and F. Vaz, Surf. Coat. Technol. 201, 7180 (2007).

26. S. Veprek and S. Reiprich, Thin Solid Films 268, 64 (1995).

27. Colorimetry, CIE Publication No. 15 Commission Internationale de L'Éclairage, Paris (1971)

28. Recommendations on Uniform Color Spaces, Difference-Difference Equations, Psychometric Color Terms, CIE Publication, Suppl. No. 2-70 Commission Internationale de L'Éclairage, Paris (1978)

29. E. Kusano, A. Satoh, M. Kitagawa, H. Canto, and A. Kinbara, Thin Solid Films 343-344, 254 (1999).

30. D. R. Lide (ed.), Handbook of Chemistry and Physics, 85 th edn., CRC Press, Florida (2004).

31. J. Alami, P. Eklund, J. Emmerlich, O. Wilhelmsson, U. Jansson, H. Högberg, L. Hultman, and U. Helmersson, Thin Solid Films 515 , 1731 (2006).

32. B. K. Karlsson, J.-E. Sundgren, and B.-O. Johansson, Thin Solid Films 87, 181 (1982).

33. F. Vaz, J. Ferreira, E. Ribeiro, L. Rebouta, S. Lanceros-Méndez, J. A. Mendes, F. Ribeiro, I. Moutinho, Ph. Goudeau, J. P. Rivière, E. Alves, K. Pischow, and J. de Rijk, Surf. Coat. Technol. 191, 317 (2005).

34. A. M. Korsunsky, M. R. McGurk, S. J. Bull, and T. F. Page, Surf Coat. Technol. 99, 171 (1998).

35. J. E. Krzanowski and S. H. Koutzaki, J. Am. Ceram. Soc. 84,672 (2001).

36. C. S. Sandu, F. Medjani, R. Sanjinés, A. Karimi, and F. Lévy, Surf. Coat. Technol. 201, 4219 (2006). 